\title{
Recovery and viability of seeds ingested by goats
}

\author{
K.C. Harrington ${ }^{1}$, W.B. Beskow ${ }^{2}$ and J. Hodgson ${ }^{1}$ \\ ${ }^{1}$ Institute of Natural Resources, Massey University, PB 11-222, Palmerston North, \\ New Zealand \\ ${ }^{2}$ CCGL Tecnologia, Rodovia RS-342 km 149, Caixa Postal 10, Cruz Alta, \\ CEP 98005-970, Brazil \\ Corresponding author: K.Harrington@massey.ac.nz
}

\begin{abstract}
Seeds of eight plant species were fed to four penned goats on three separate occasions. The faeces were collected over subsequent days, then seeds were recovered and tested for viability. Less than $10 \%$ of the ingested seeds survived passage through the goats for five of the species, though $32.3 \%$ of broad-leaved dock (Rumex obtusifolius) seeds and $19.2 \%$ of gorse (Ulex europeaus) seeds were excreted undigested. The percentage of viable seeds ingested that remained viable when excreted ranged from $25.7 \%$ for broad-leaved dock to $0.5 \%$ for variegated thistle (Silybum marianum). A large proportion of recovered seeds was excreted within $24 \mathrm{~h}$ of ingestion, and all seeds had passed through the goats within $72 \mathrm{~h}$. Grazing by goats of weed seed-heads is generally seen as beneficial due to large decreases in the number of viable seeds added to the soil. However, as all species established from intact goat dung, potential exists for dispersal of weeds to new areas, especially by feral goats.
\end{abstract}

Keywords goats, grazing, pasture weeds, seeds, dormancy, gorse, thistles.

\section{INTRODUCTION}

Goats have been used for many years to eat woody weed species not favoured by sheep and cattle, and have been used for control of blackberry (Rubus fruticosus) in New Zealand since at least 1906 (Fawcett 1925). Compared with sheep, goats tend to browse on shrubs rather than graze at ground level, and also have a complete upper lip that is muscular and lacking the dividing philtrum of sheep, favouring the grasping and tearing of browse (Smith \& Sherman 1994). Scrub weeds controlled by goats include gorse (Ulex europeaus) (Clark et al. 1982), broom (Cytisus scoparius) (Holst et al. 2004) and manuka (Leptospermum scoparium) (Rolston et al. 1983).

Goats also feed on some herbaceous weeds avoided by other livestock, especially thistle species such as Californian thistle (Cirsium arvense) (Rolston et al. 1983), Scotch thistle (Cirsium vulgare) (Davidson 1990) and variegated thistle (Silybum marianum) (Campbell et al. 1979). Other components of pasture that are often eaten by goats but avoided by other animals include broad-leaved dock (Rumex obtusifolius) (Sakanoue et al. 1995), ragwort (Jacobaea vulgaris) (Cheeke 1984) and the seed-heads of grasses (Pozo et al. 1998).

If goats eat the seed-heads of weeds, they are potentially reducing the number of viable seeds entering the soil seed-bank, but only if the seeds are destroyed as they pass through the digestive tract. Only limited information has been published on the fate of seeds passing through goats, especially for species found in New Zealand pastures. For example, Holst \& 
Allan (1996) recovered only $0.2 \%$ of the viable seeds of nodding thistle (Carduus nutans) and $10 \%$ of broom seeds fed to goats. They also found the seeds took some time to be eliminated, with the peak of excretion occurring on the third day following feeding, and 6 days were required for all seeds to be passed out.

The objectives of the present trial were to investigate how effectively seeds from a range of common New Zealand pasture and weed species are destroyed by goats, and to determine how quickly they are excreted. This study also investigated whether seedlings could establish successfully from within intact dung pellets, and if the dormancy of seeds changed with passage through goats.

\section{MATERIALS AND METHODS}

Seeds were obtained of two pasture species (perennial ryegrass (Lolium perenne) and white clover (Trifolium repens)) and six weed species (Californian thistle, Scotch thistle, variegated thistle, broad-leaved dock, narrow leaved plantain (Plantago lanceolata) and gorse). For each seedlot, the 1000-seed weight was measured by weighing four samples of 100 seeds per species, and the average seed length was measured using an eye-piece micrometer for ten seeds per species. The germination percentage of each seed lot was determined just prior to commencement of the trial using standard procedures (ISTA 1996), with those seeds not germinating in Petri dishes within the recommended time being checked for viability using a tetrazolium test and for hardseededness by careful observation of whether seeds had imbibed.

Four 2-year-old Boer-Angora cross goats were selected at random from a farmed herd in September 1998, drenched for worms then held indoors at the Animal Physiology Unit of Massey University, Palmerston North, in metabolism crates. They were offered lucerne (Medicago sativa) chaff and water ad libitum, and observed for 2 weeks before the commencement of the trial to ensure habituation with the new feed and environment, as well as to allow for any seeds ingested in the field to be eliminated. The lucerne chaff was sampled daily prior to being fed to animals and screened to ensure no seeds of the species being tested in the trial were present. Goats averaged $22 \mathrm{~kg}( \pm \mathrm{SE} 1.1 \mathrm{~kg})$ at the end of the habituation period, and ate $850 \mathrm{~g}$ ( \pm SE $43 \mathrm{~g}$ ) dry matter of chaff per goat daily.

Each goat was then given a single feed of 8000 seeds, containing 1000 seeds from each of the eight plant species. This resulted in a volume equivalent to a handful of seeds $(38.6 \mathrm{~g})$, which were thoroughly mixed with $50 \mathrm{~g}$ of molasses and fed to animals in individual bowls, ensuring all seeds were consumed before being returned to their lucerne chaff diet. Faeces were collected at 24-hour intervals for the 6 days after ingestion from screen trays placed permanently under each crate, then thoroughly mixed by hand and weighed. Two samples of $25 \%$ of the total weight were taken, one for seed recovery and the other for testing whether the seeds would germinate from intact faecal pellets. This process of feeding seeds and subsequently collecting faeces was conducted three times at weekly intervals over successive weeks.

To recover seeds from faeces, the faecal pellets were soaked in water overnight, then washed carefully through a $0.5 \mathrm{~mm}$ mesh before being searched for seeds. These seeds were then identified and tested for viability and ability to germinate using the standard procedures mentioned above (ISTA 1996). When no further seeds could be found, the remaining material was spread in $5 \mathrm{~mm}$-deep layers on top of sterile potting mix in a glasshouse and checked for the next 3 months for seedlings, which were identified and counted.

The second sub-sample of faecal pellets was laid intact in layers $1 \mathrm{~cm}$ deep on sterile potting mix in labeled pots within a glasshouse to determine whether germination was possible directly from faecal pellets. They were watered regularly for 5 months and seedlings were identified and counted as they appeared.

All data were subjected to an analysis of variance within SAS, using a randomised block design, with each combination of goat and week of feeding regarded as a block, giving a total of 12 
blocks. A linear regression analysis investigated the relationship between seed size and safe passage of seeds through the goats.

\section{RESULTS}

The percentage of seeds fed to the goats that were recovered intact from the faeces ranged from $0.6 \%$ for variegated thistle to $32.3 \%$ for broad-leaved dock (Table 1). Most seeds were successfully located by inspecting the faeces, with only $0-3 \%$ further seeds being found by germination from sorted faecal material for six of the species (data not presented). However, 17\% of recovered perennial ryegrass seeds and $11 \%$ of recovered Californian thistle seeds were missed during sorting and later detected by germination.

The seed size varied substantially between species, ranging from a 1000 -seed weight of $0.63 \mathrm{~g}$ for white clover to $19.4 \mathrm{~g}$ for variegated thistle, and likewise seed length varied from $1.4 \mathrm{~mm}$ to $6.9 \mathrm{~mm}$ (Table 1). Despite the two species with the longest seeds having the least seeds pass through the goats undigested, regression analysis found no significant $(\mathrm{P}>0.05)$ relationship between seed size (weight or length) and successful passage through the goats.

Not all of the seeds fed to the goats were viable prior to ingestion (Table 2). Those seeds that were excreted intact were tested for viability (Table 2), and those that were viable are presented in Table 1 expressed as a percentage of the viable seeds ingested. The percentage of viable seeds passing through the goats in a viable state varied between species in a very similar manner to the total seed recovery, ranging from $25.7 \%$ for broad-leaved dock down to $0.5 \%$ for variegated thistle.

Another measure of how successfully seeds passed through goats was a count of seedlings that grew on intact goat faecal pellets. As might be expected, the number of seedlings present on the faecal deposits was less than the number of viable seeds calculated to have been present (Table 1), but there were healthy seedlings of all species present on the dung. Once again, broad-leaved dock and gorse had the most seedlings present.

Dormancy levels of seeds for each species were also determined before and after passage through the goats (Table 2), although insufficient seeds were obtained from the dung for some species to properly analyse dormancy levels. Dormancy appeared to decrease in most species where this could be measured. Although less of the gorse seeds were hard seeded after passage through the goats, many did still have intact hard seed coats. Most seeds (average of $73.9 \%$ ) passed through

Table 1 The mean size (1000-seed-weight and length) of seeds fed to goats, and the mean survival of these after passing through the goats, expressed as percentage of whole seeds recovered in the dung, the percentage of viable seeds ingested that remained viable, and the percentage of viable seeds ingested that formed seedlings on dung deposits left in plant pots.

\begin{tabular}{lccccc}
\hline Species & $\begin{array}{c}\text { 1000-seed } \\
\text { weight }(\mathrm{g})\end{array}$ & $\begin{array}{c}\text { Length } \\
(\mathrm{mm})\end{array}$ & $\begin{array}{c}\text { Recovery } \\
(\%)\end{array}$ & $\begin{array}{c}\text { Viable seeds } \\
(\%)\end{array}$ & $\begin{array}{c}\text { Seedlings } \\
(\%)\end{array}$ \\
\hline broad-leaved dock & 1.83 & 2.57 & 32.3 & 25.7 & 4.31 \\
gorse & 6.23 & 3.05 & 19.2 & 19.3 & 2.12 \\
Californian thistle & 0.88 & 3.31 & 10.4 & 5.6 & 0.42 \\
narrow-leaved plantain & 2.32 & 2.93 & 8.2 & 5.8 & 1.12 \\
Scotch thistle & 2.66 & 3.86 & 6.0 & 4.4 & 0.68 \\
white clover & 0.63 & 1.38 & 3.9 & 2.6 & 0.24 \\
perennial ryegrass & 2.67 & 5.70 & 1.9 & 1.6 & 0.31 \\
variegated thistle & 19.42 & 6.92 & 0.6 & 0.5 & 0.12 \\
\hline LSD $(\mathrm{P}=0.05)$ & 0.12 & 0.29 & 7.7 & 7.5 & 1.43 \\
\hline
\end{tabular}


Table 2 The percentage of seeds both before ingestion and after excretion from goats that gave normal seedlings or were dormant during germination tests (with the remainder being dead seeds or those producing abnormal seedlings).

\begin{tabular}{|c|c|c|c|c|c|c|}
\hline \multirow[b]{2}{*}{ Species } & \multicolumn{3}{|c|}{ Before ingestion } & \multicolumn{3}{|c|}{ After excretion } \\
\hline & Normal & Dormant & Total & Normal & Dormant & Total \\
\hline broad-leaved dock & 94.0 & 2.0 & 96.0 & 76.6 & 0.1 & 76.7 \\
\hline gorse & 7.5 & 85.5 & 93.0 & 16.5 & 77.0 & 93.5 \\
\hline Californian thistle & 83.0 & 3.5 & 86.5 & 40.0 & 0.0 & 40.0 \\
\hline narrow-leaved plantain & 97.5 & 1.0 & 98.5 & 66.6 & 0.5 & 67.1 \\
\hline Scotch thistle & 42.0 & 7.0 & 49.0 & 34.6 & 0.0 & 34.6 \\
\hline white clover & 98.0 & 2.0 & 100.0 & IS $^{1}$ & IS & IS \\
\hline perennial ryegrass & 86.0 & 0.0 & 86.0 & IS & IS & IS \\
\hline variegated thistle & 79.0 & 2.0 & 81.0 & IS & IS & IS \\
\hline $\operatorname{LSD}(\mathrm{P}=0.05)$ & 8.4 & 5.1 & 9.3 & 12.0 & 1.7 & 12.3 \\
\hline
\end{tabular}

${ }^{1} \mathrm{IS}=$ Insufficient seeds for valid replicated germination tests.

the digestive system in the first $24 \mathrm{~h}$, although it took up to $72 \mathrm{~h}$ for all seeds to be excreted (Table 3). All seeds of perennial ryegrass, variegated thistle and Californian thistle were recovered within $48 \mathrm{~h}$, while the other species took up to $72 \mathrm{~h}$ to be excreted. No seeds were found after $72 \mathrm{~h}$, with the exception of one seed of variegated thistle, which was found in a sample collected between 72 and $96 \mathrm{~h}$. Although on average only $5.1 \%$ of seeds were recovered between 48 and $72 \mathrm{~h}$, white clover did appear to take longer than most species to pass through goats, with $17.2 \%$ of recovered seeds passing through after $48 \mathrm{~h}$.

Table 3 The period of time after weed seeds were fed to goats that they were collected within faecal samples, expressed as a percentage of the seeds that were ingested by the goats.

\begin{tabular}{lccc}
\hline Species & $0-24 \mathrm{~h}$ & $24-48 \mathrm{~h}$ & $48-72 \mathrm{~h}$ \\
\hline broad-leaved dock & 23.4 & 7.5 & 1.4 \\
gorse & 16.4 & 2.6 & 0.4 \\
Californian thistle & 8.4 & 2.1 & 0.0 \\
narrow-leaved & 7.0 & 1.4 & 0.1 \\
plantain & & & \\
Scotch thistle & 4.8 & 1.1 & 0.1 \\
white clover & 2.9 & 0.7 & 0.3 \\
perennial ryegrass & 1.7 & 0.1 & 0.0 \\
variegated thistle & 0.5 & 0.1 & 0.0 \\
\hline LSD $(\mathrm{P}=0.05)$ & 6.1 & 1.7 & 0.5 \\
\hline
\end{tabular}

\section{DISCUSSION}

Although viable seeds were recovered from the goat faeces, these results show that goats do successfully destroy a large proportion of the weed seeds that they consume. Of particular interest is their efficiency at destroying thistle species, since goats are known to eat their flower and seed-heads. The present results suggest that $94 \%$ of all viable seeds of Californian thistle are destroyed by their passage through goats. Destruction is even more pronounced for Scotch thistle (96\%) and variegated thistle (99.5\%), as shown in Table 1. Even for those species that had a number of viable seeds within goat faeces, $81 \%$ of viable gorse seeds and $74 \%$ of broad-leaved dock seeds were destroyed while passing through goats, thus considerably reducing the number of seeds entering the soil seed bank. Depending on goat stocking rates, most of the flower-heads of these weeds are eaten before viable seeds have formed (Beskow 2001), and no further seeds will probably be produced by eaten stems, thus further reducing the seed rain.

Simao Neto et al. (1987) found a negative linear relationship between seed size and the percentage of seeds recovered following passage through goats. Although the two longest seeds in the present trial had the lowest recovery, no significant relationship was found as white clover, the species with the smallest seeds, also had a low 
recovery rate. Larger seeds might be more likely to get damaged than smaller seeds by chewing during rumination.

Many of the gorse seeds that were not hardseeded prior to ingestion by goats were probably destroyed, whereas those that had a hard seed coat survived passage through the digestive tract; the acids within the tract probably helped scarify some of these hard seed coats, leaving them ready to germinate once excreted (Baeza \& Vallejo 2006). Although insufficient white clover seeds remained after passing through the goats to give meaningful results on dormancy, most of the seeds collected were hard-seeded, suggesting that only the few seeds that had a hard seed coat before being fed to goats survived passage through them. As the white clover seeds were obtained from a commercial source, they had been scarified prior to sale, explaining the low percentage of hard seeds initially.

Although most of the seeds in the present trial were excreted within $24 \mathrm{~h}$, this appears to be faster than recorded in other trials. Simao Neto et al. (1987) calculated that the time taken for 50\% of recovered seeds to pass through goats varied from $40 \mathrm{~h}$ to $54 \mathrm{~h}$, depending on the plant species, with the peak of excretion between 24 and $48 \mathrm{~h}$. With leafy spurge (Euphorbia esula), Lacey et al. (1992) found similar excretion rates between 24 and $48 \mathrm{~h}$ as during the first $24 \mathrm{~h}$, with the last seeds being excreted between 4 and 5 days after feeding. Holst \& Allan (1996) found nodding thistle and broom seed excretion from goats peaked between 48 and $72 \mathrm{~h}$ after feeding. In all four trials, animals were penned for the duration of the trial and fed chaffed lucerne.

Because some seeds did pass through goats in a viable state, and as these seeds were able to establish directly from goat faecal pellets, there is some potential for goats to disperse weed species to new areas. For farmed goats, this might not be a major problem, as goats will often eat seed-heads of weeds such as thistles first after being released into a paddock (Beskow 2001), thus the seeds may be excreted before animals are moved on to a new paddock. However, with feral goats that jump fences, seed dispersal to new areas could be a problem as goats have been estimated to walk up to $9 \mathrm{~km}$ each day (Arnold \& Dudzinski 1978). Even if only $2-4 \%$ of ingested seeds are excreted in a viable state, often many hundreds of seeds are present in each seed-head eaten for species such as thistles, potentially leading to movement of the species several kilometres from where they were ingested.

\section{ACKNOWLEDGEMENTS}

This research was supported by funding from CAPES (Ministry of Education, Brazil), Massey University Graduate Research Fund, Riverside Farm Research Fund, Primary Follicle Trust and New Zealand Cashgora Farmers Inc. The authors wish to thank Angela Beskow for technical assistance, the AgResearch Flock House Agricultural Centre for loan of the animals, and the Massey University Seed Tech Services for assistance with seed cleaning and testing.

\section{REFERENCES}

Arnold GW, Dudzinski ML 1978. Ethology of free-ranging domestic animals: Ethology of free-ranging domestic animals. Elsevier Scientific Publishing Co., Amsterdam; New York, USA Netherlands. xi +198 p.

Baeza MJ, Vallejo VR 2006. Ecological mechanisms involved in dormancy breakage in Ulex parviflorus seeds. Plant Ecology 183: 191-205.

Beskow WB 2001. Integration of goats into sheep and cattle grazing systems as a permanent weed control tool. $\mathrm{PhD}$ thesis, Massey University, Palmerston North. 206 p. http:// muir.massey.ac.nz/handle/10179/2091

Campbell MH, Holst PJ, Auld BA, Medd RW 1979. Control of three pasture weeds using goats. Proceedings of the 7th Asian-Pacific Weed Science Society Conference, Sydney, Australia. Pp. 201-205.

Cheeke PR 1984. Comparative toxicity and metabolism of pyrrolizidine alkaloids [tansy ragwort (Senecio jacobaea)] in ruminants and nonruminant herbivores. Canadian Journal of Animal Science 64: 201-202. 
Clark DA, Lambert MG, Rolston MP, Dymock N 1982. Diet selection by goats and sheep on hill country. Proceedings of the New Zealand Society of Animal Production 42: 155-157.

Davidson S 1990. Goats help eliminate thistles. Rural Research: 16-19.

Fawcett EJ 1925. Goats and blackberry control on hill country. New Zealand Journal of Agriculture 31: 9-12.

Holst PJ, Allan CJ 1996. Targeted grazing of thistles using sheep and goats. Plant Protection Quarterly 11:271-273.

Holst PJ, Allan CJ, Campbell MH, Gilmour AR 2004. Grazing of pasture weeds by goats and sheep. 2. Scotch broom (Cytisus scoparius L.). Australian Journal of Experimental Agriculture 44: 553-557.

ISTA 1996. International rules for seed testing. Rules 1996. Seed Science and Technology 24: 1-335.

Lacey JR, Wallander R, Olson-Rutz K 1992. Recovery, germinability, and viability of leafy spurge (Euphorbia esula) seeds ingested by sheep and goats. Weed Technology 6: 599-602.
Pozo M, Osoro K, Celaya R 1998. Effects of complementary grazing by goats on sward composition and on sheep performance managed during lactation in perennial ryegrass and white clover pastures. Small Ruminant Research 29: 173-184.

Rolston MP, Clark DA, Lambert MG 1983. Scrub and coarse weed control by goats and sheep: Ballantrae trial. Proceedings of the Ruakura Farmers Conference: 55-57.

Sakanoue S, Kitahara N, Hayashi H 1995. Biological control of Rumex obtusifolius L. by goat grazing. Japan Agricultural Research Quarterly 29: 39-42.

Simao Neto M,Jones RM, RatcliffD 1987.Recovery of pasture seed ingested by ruminants. 1 . Seed of six tropical pasture species fed to cattle, sheep and goats. Australian Journal of Experimental Agriculture 27: 239-246.

Smith MC, Sherman DM 1994. Goat medicine. Lea \& Febiger, Philadelphia. 620 p. 